\title{
Utopias compartilhadas em práxis
}

Camila Lima Coimbra ${ }^{1}$ Nima Imaculada Spigolon ${ }^{2}$

A utopia, porém, não seria possível se faltasse a ela o gosto da liberdade, embutido na vocação para a humanização. Se faltasse também a esperança sem a qual não lutamos. (FREIRE, 1992, p. 51).

A utopia freireana, em seu sentido mais radical, entrelaça a ideia de humanização, liberdade e esperança. Essas palavras, quando não são apenas palavras, mas práxis, reverberam na construção de um projeto de sociedade justa, democrática, laica e inclusiva. Só afiançadas na ideia do "Estado de Direito", conseguimos nos comprometer e lutar por uma educação transformadora, dialógica, libertadora. Assim caminhamos por horizontes de utopia!

Nesse movimento, surge a proposição de uma Edição Especial da Revista Educação Popular, em comemoração ao "Centenário Paulo Freire" que mobiliza, além de nossa história, dois projetos de extensão: o primeiro intitulado "Inéditos viáveis na formação de professores/as", que cria o Círculo de Estudos e Pesquisas Freireanos (CEPF); o outro denominado "Centenário Freireano Circulante", ambos registrados nos Siex/UFU sob os números 21910 e 23160, respectivamente.

O Centenário Freireano Circulante, uma "utopia verdadeira", nasce e se esperança na junção de muitas gentes e instituições que planejaram e realizaram o ano inteiro de comemorações, mensalmente, sempre próximo aos dias 18 (aniversário de Elza Freire) ou 19 (aniversário de Paulo Freire). De janeiro a dezembro foram realizadas várias atividades como: "Café com pipoca", "Mesas dialógicas", Jornada e muitos eventos históricos na educação, que fizeram as suas homenagens ao Centenário. Um ano inteiro de comemoração.

Ainda no finalzinho de 2020, a Universidade Federal de Uberlândia e a Universidade Estadual de Campinas criaram, por meio das Faculdades de Educação e da

\footnotetext{
1 Doutora em Educação pela Universidade Católica de São Paulo, Brasil; professora associada da Faculdade de Educação da Universidade Federal de Uberlândia, Minas Gerais, Brasil; pesquisadora do Grupo de Pesquisa Curriculum (PUC), do Observatório de Políticas Públicas (OPP/UFU) e do Grupo de Estudos e Pesquisa em Avaliação Educacional (GEPAE/UFU). E-mail: camilima8@gmail.com.

2 Doutora em Educação pela Universidade Estadual de Campinas, São Paulo, Brasil; professora da Faculdade de Educação da Universidade Estadual de Campinas, São Paulo, Brasil; coordenadora e pesquisador do Grupo de Estudos e Pesquisa em Educação de Jovens e Adultos (GEPEJA/Unicamp) e do Grupo de Pesquisa em Política, Educação e Sociedade (GPPES/Unicamp). E- mail: nima@unicamp.br.
} 
arte de Felipe Menegheti, um selo ${ }^{3}$ em comemoração aos 100 anos de Paulo Freire e 105 anos de Elza Freire. Esse selo carrega em nossa história as possibilidades e os encontros que temos em nossas vidas profissionais e afetivas. O selo marca a agenda das comemorações institucionais e em redes profissionais, acadêmicas, relacionais e freireanas no Brasil e pelo mundo. Como dissemos, no texto de lançamento:

\begin{abstract}
Dois em um. Um em muitos. Muitos em dois. Trocadilho para iniciar uma categoria fundamental para a compreensão do pensamento freireano: a ideia de um sujeito histórico, que se faz a partir e com suas experiências, formação, trajetória vivenciadas nas relações sociais, constituindo-se, assim, em cada identidade cultural presente na diversidade da realidade brasileira. Se assim somos, identificamos no pensamento de Paulo a presença, a convivência, a permanência, a influência da educadora Elza ${ }^{4}$.
\end{abstract}

Se assim somos, também identificamos em nós, "a convicção de que a mudança é possível" e de que "ensinar exige a corporeificação das palavras pelo exemplo". Dois saberes importantes para nossa práxis, para nossa reflexão, para a ampliação de nossa leitura de mundo. Leitura com...

As autoras que entrelaçam também em suas vidas a liberdade como forma de humanização, se conheceram em 2008, na Faculdade de Ciências Integradas do Pontal (Facip-UFU), em Ituiutaba, Minas Gerais, por meio de um Círculo de Cultura que queríamos realizar no Curso de Pedagogia. Um projeto pedagógico criado a partir de princípios freireanos, com ciclos de formação que realizam as sínteses provisórias por meio de Círculos de Cultura. Essa ideia de circular no mundo com, na conexão, desde lá, não despregou da gente... Nesse centenário, completamos 12 anos de uma aproximação em-Freires. "É a leitura do mundo exatamente a que vai possibilitando a decifração cada vez mais crítica da ou das situações-limites, mais além das quais se acha o inédito viável". (FREIRE, 1992, p. 51). Achar os inéditos viáveis nessa "utopia verdadeira" talvez tenha sido nosso caminho. Afinal o que seria uma utopia verdadeira?

3 O selo é gratuito, democrático e público. Link para acesso e download: https://www.fe.unicamp.br/portal-paulo-freire/2021.

${ }^{4}$ CONGREGAÇÃO DA FACULDADE DE EDUCAÇÃO DA UNICAMP. Deliberação n. 253, de 16 de dezembro de 2020. Deliberação pela aprovação da criação do selo comemorativo do centenário Paulo Freire e 105 anos de Elza Freire por Nima I. Spigolon e Camila L. Coimbra; arte de Felipe Menegheti. Campinas: FE-UNICAMP, 2020. Disponível em https://www.fe.unicamp.br/portal-paulo-freire/2021. 
Por isso, venho insistindo, desde a Pedagogia do oprimido, que não há utopia verdadeira fora da tensão entre a denúncia de um presente tornando-se cada vez mais intolerável e o anúncio de um futuro a ser criado, construído, política, estética e eticamente, por pós, mulheres e homens. (FREIRE, 1992, p. 47, grifo nosso).

A partir dessas relações utópicas, em que partilhamos sonhos, afetos e desejos destaca-se como intencionalidades dessas comemorações em torno do Centenário: o resgate da memória de Paulo Freire; a reflexão crítica sobre sua vida e obra; a análise da realidade, a partir da denúncia e do anúncio de proposições para a educação brasileira, para a formação de professores/as em uma perspectiva freireana.

Frente a isso, compreendemos que a materialização de uma Edição Especial da Revista de Educação Popular em comemoração ao Centenário de Paulo Freire, justificase ao reconhecer sua importância e distinção como Patrono da Educação Brasileira, conforme Lei $\mathrm{n}^{\mathrm{o}}$ 12.612, de 13 de abril de 2012. Assim, anunciamos o destaque de Gadotti (2017), ao papel da Revista:

Destaque-se ainda a notável experiência da Pró-Reitoria de Extensão, Cultura e Assuntos Estudantis ${ }^{5}$ da Universidade Federal de Uberlândia (UFU), que tem como princípio básico a efetiva interação dialógica com a Sociedade, seja para se situar historicamente, seja para se identificar culturalmente ou para referenciar sua formação acadêmica. A UFU mantém, há mais de 15 anos, a Revista de Educação Popular, priorizando abordagens e análises que tratam sobre a produção nos campos da educação, da saúde e da cultura populares. A extensão universitária na UFU segue os princípios da articulação das ações entre a universidade e a sociedade, atuando de forma interativa, desencadeando processos de troca entre saber popular e acadêmico e aplicando metodologias participativas, com vistas a uma atuação transformadora, voltada para os interesses e necessidades da maioria da população. (GADOTTI, 2017, p. 12 grifos e nota das autoras).

Uma Revista destacada nacionalmente, como participante da defesa da universidade pública, gratuita, laica e inclusiva, "voltada para os interesses e necessidades da maioria da população", recebe, nesta edição tão especial, a temática: “A práxis educativa em uma perspectiva freireana". Mas em qual perspectiva? "O compromisso seria uma palavra oca, uma abstração, se não envolvesse a decisão lúcida e profunda de quem o assume. Se não se desse no plano do concreto" (FREIRE, 1979, p.7). Esse compromisso que nos une em torno de um ato que "se construa em

\footnotetext{
${ }^{5}$ Em 2016, por meio da Resolução CONSUN UFU nº 06/2016, a Universidade Federal de Uberlândia cria a Pró-reitoria de Assuntos Estudantis.
} 
compromisso". A práxis une o pensar e o agir, nesse comprometimento social, histórico e cultural. O ato, o agir, o pensar, o exemplo, a práxis são componentes de uma busca permanente.

O que não podemos, como seres imaginativos e curiosos, é parar de aprender e de buscar, de pesquisar a razão de ser das coisas. Não podemos existir sem nos interrogar sobre o amanhã, sobre o que virá, a favor de que, contra que, a favor de quem, contra quem virá; sem nos interrogar em torno de como fazer concreto o "inédito viável" demandando de nós a luta por ele. (FREIRE, 1992, p. 51)

A luta pelo inédito viável, para driblar as situações limites, são condição para o trabalho e a ação educativa nesse contexto de pandemia e também e ao mesmo tempo, de uma crise político-civilizatória. Para qual mundo caminhamos? Para qual amanhã? Pensamos que o material organizado em torno dessa temática possa ser lido como inéditos viáveis, cada um em sua realidade, com os sujeitos que refletem e transformam o seu mundo e o mundo do outro.

Essa categoria da práxis está localizada na indissociabilidade freireana entre as ideias e a ação, pois a primeira condição para que um ser humano possa assumir um ato comprometido está na nossa capacidade de agir e refletir. "É exatamente esta capacidade de atuar, operar, de transformar a realidade de acordo com finalidades propostas pelo homem (e mulher), a qual está associada sua capacidade de refletir, que o faz um ser da práxis" (FREIRE, 1979, p. 13). Um ser da práxis que lê o mundo:

É por isso que o problema real que se nos coloca não é o de insistir numa teimosia sem sucesso - a de afirmar a neutralidade impossível da educação, mas reconhecendo sua politicidade, lutar pela postura ético-democrática de acordo com a qual educadoras e educadores, podendo e devendo afirmar-se em seus sonhos, que são políticos, se impõem, porém: a) deixar claro aos educandos que há outros sonhos contra os quais, por várias razões a ser explicadas, os educadores ou as educadoras podem até lutar; b) que os educandos têm o direito de ter o dever de ter os seus sonhos também, não importa que diferentes ou opostos aos de seus educadores. (FREIRE, 2001, p. 21).

Anuncia-se, assim, a educação como uma ação política e o sonho como atitude para educandos/as e educadores/as. Esse princípio configura-se na compreensão de que o processo educativo tem um caráter político que precisa ser identificado, ou seja, "não há nem jamais houve prática educativa em espaço e tempo nenhum de tal maneira 
neutra, comprometida apenas com ideias preponderantemente abstratas e intocáveis" (FREIRE, 1992, p.78). Entende-se, assim, a educação como um conceito político:

É na diretividade da educação, esta vocação que ela tem, como ação especificamente humana, de endereçar-se até sonhos, ideais, utopias e objetivos, que se acha o que venho chamando politicidade da educação. A qualidade de ser política, inerente à sua natureza. (FREIRE, 1996, p. 110).

Assumindo a politicidade da educação, compartilhamos nossas referências a partir de uma pedagogia progressista, que acredita e propõe uma transformação da sociedade, por meio da educação, para uma vida e uma convivência justa, diversa, democrática e libertadora.

Desta forma, inspiradas na possibilidade da reinvenção freireana, anunciamos, com esta edição especial, mais uma forma de com-memorar a importância de Paulo Freire em um movimento revolucionário de contraposição a um governo antidemocrático, como o que se instaurou no Brasil a partir de 2019, incluindo o golpe de 2016, com o impeachment da presidenta Dilma Rousseff. Resistir a esse projeto antidemocrático é outro princípio inspirador em Freire na atualidade, pois para ele "a própria essência da democracia envolve uma nota fundamental, que lhe é intrínseca - a mudança" (FREIRE, 1967, p. 97). E continua “ora, a democracia e a educação democrática se fundam ambas, precisamente, na crença no homem (e na mulher). (FREIRE, 1967, p. 103).

Somos professores/as/educadores/as em processos de formação humana! Engajados na/com/para formação (humana, sensível e crítica) de formadores/as inseridos/as no compromisso social da Educação Pública. E assim, seres mais humanos, mais humanizadores.... mais gente!!!

Por acreditar na vida, no homem, nas mulheres, nas crianças, nos jovens, nas gentes que nos tornamos, somos seres também de esperança e de construção de utopias, de sonhos, de inéditos viáveis. Desejamos uma boa leitura. Sintam-se convidados/as a uma práxis educativa revolucionária.

Primavera 2021.

Camila e Nima 


\section{Referências}

COIMBRA, C. L.; SPIGOLON, N. Inspirações e práxis freireana: contribuições de Elza Freire para o diálogo e a convivência. Caderno de Textos do GEPEJA, Campinas, v. 1, p. 78-86, 2010.

COIMBRA, C. L.; RICHTER, L. M. Sons, imagens e contatos na tessitura do Círculo de Cultura: espaço-tempo de aprendizagem criativa. In: SPIGOLON, N. I.; CAMPOS, C. B. G. (org.). Círculos de cultura: teorias, práticas e práxis. Curitiba: CRV, 2016. p. 141-158.

COIMBRA, C. L. Categorias freireanas na práxis. e-Mosaicos, v. 6, p. 55-67, 2017. Doi: 10.12957/e-mosaicos.2017.31162. Disponível em: https://www.epublicacoes.uerj.br/index.php/e-mosaicos/article/view/31162 . Acesso em: 15 jul. 2021.

FREIRE, P. Educação como prática da liberdade. Introdução de Francisco C. Weffort. Rio de Janeiro, Paz e Terra, 1967.

FREIRE, P. Educação e mudança. Prefácio de Moacir Gadotti. Tradução de Lilian Lopes Martin. Rio de Janeiro-RJ. Paz e Terra, 1979.

FREIRE, P. Pedagogia da esperança: um reencontro com a Pedagogia do Oprimido. Rio de Janeiro-RJ: Paz e Terra, 1992.

FREIRE, P. A importância do ato de ler. Prefácio de Antonio Joaquim Severino. São Paulo: Cortez: Autores Associados, 2001.

FREIRE, P. Pedagogia da autonomia. Prefácio de Edna Castro de Oliveira. Rio de Janeiro-RJ: Paz e Terra, 1996.

GADOTTI, M. Extensão universitária: para quê? Disponível em: https://www.paulofreire.org/images/pdfs/Extens\%C3\%A3o_Universit\%C3\%A1ria__Moacir_Gadotti_fevereiro_2017.pdf. Acesso em: 2 set. 2021.

SPIGOLON, N. I. Pedagogia da convivência: Elza Freire uma vida que faz educação. Jundiaí: Paco Editorial: 2016.

SPIGOLON, N. I.; CAMPOS, C. B. G. (org.). Círculos de cultura: teorias, práticas e práxis. Curitiba: CRV, 2016. 